\title{
A UTILIZAÇÃO DAS NOVAS TECNOLOGIAS EM UMA ESCOLA EXPERIMENTAL DO RIO DE JANEIRO
}

\author{
THE USE OF NEW TECHNOLOGIES IN AN EXPERIMENTAL \\ SCHOOL OF RIO DE JANEIRO
EL USO DE LAS NUEVAS TECNOLOGÍAS EN UNA ESCUELA EXPERIMENTAL DE RIO DE JANEIRO

\author{
Diego Luz Moura ${ }^{1}$ \\ Cleyton Batista de Sousa ${ }^{2}$
}

\begin{abstract}
RESUMO: A utilização das novas tecnologias no ambiente educacional é considerada uma competência inovadora para o ensino. A escola ao dialogar com a cultura deve incorporar essa forma de comunicação na sua forma de fazer ver o mundo. No Rio de Janeiro, a Educopédia tem sido uma estratégia interessante. Investigamos alunos de uma escola experimental que usam esse recurso desde 2010. Foi feito um levantamento de opiniões do tipo survey de natureza quantitativa. Para a coleta dos dados foi utilizada a técnica Delphi para a construção de um escala Likert. Utilizamos três rounds consecutivos para alcançarmos um consenso entre os informantes. A amostra da entrevista nos três rounds foi composta por 50 alunos, sendo 25 do sexo masculino e 25, do feminino. Os alunos apoiam a inserção das novas tecnologias na escola e sugerem que essa poderia ser mais explorada. Observamos que a Educopédia ainda não é largamente utilizada nas aulas. Todas as disciplinas possuem baixa utilização na percepção dos alunos, com destaque para inglês, educação musical e educação física. Entendemos que tal recurso necessita de ajustes em sua aplicação. É necessário maior foco no processo de formação de docentes para atuarem com as novas tecnologias. Os jogos são um dos recursos da Educopédia que os alunos mais gostam e ao mesmo tempo, o que menos usam nas aulas. Isso ilustra que falta uma estratégia que busque reconhecer o perfil e o interesse dos discentes.
\end{abstract}

PALAVRAS-CHAVE: Novas tecnologias. Avaliação. Currículo.

ABSTRACT: The use of new technologies in the educational environment is considered an innovative competence for teaching. The dialogue with the school culture must incorporate this form of communication in your way to see the world. In Rio de Janeiro, the Educopédia has been an interesting strategy. Investigated an experimental school students who use this resource since 2010. The methodology of this research was a survey of opinions of the type of quantitative survey. For data collection the Delphi technique for the construction of a Likert scale was used. We used 3 consecutive rounds to reach a consensus among informants. A sample of the interview in 3 rounds consisted of 50 students, 25 males and 25 females. Students support the insertion of new technologies in school and suggest that this could be explored further. We observed that the Educopédia is still not widely used in the classroom. All courses have low utilization in the perception of the students, especially English, physical education and music education. We believe that this feature requires adjustments in your

\footnotetext{
${ }^{1}$ Doutor em Educação Física pela Universidade Gama Filho. Professor do Colegiado de Educação Física da Universidade Federal do Vale do São Francisco. Petrolina (PE). E-mail: diego.luz@ univasf.edu.br

${ }^{2}$ Graduado em Educação Física pela Universidade Gama Filho. Mestrando do Programa de Pós Graduação Ciências da Saúde e Biológicas da Universidade Federal do Vale do São Francisco. Petrolina (PE). E-mail: cleytonbatista1@hotmail.com
}

Submetido em: 25/07/2014 - Aceito em: 06/08/2014.

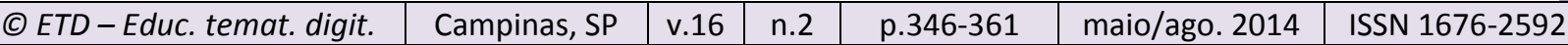


application. Greater focus on training teachers to work with the new process technologies is required. Games are one of the Educopédia resources that students like and at the same time, the least use in the classroom. This illustrates that lack a strategy that seeks to recognize the profile and interest of students.

Keywords: New technologies. Evaluation. Currculum.

Resumen: El uso de las nuevas tecnologías en el ámbito educativo se considera una competencia innovadora para la enseñanza. El diálogo con la cultura de la escuela debe incorporar esta forma de comunicación en su manera de ver el mundo. En Río de Janeiro, el Educopédia ha sido una estrategia interesante. Investigado un estudiantes de las escuelas experimentales que utilizan este recurso desde 2010. La metodología de esta investigación fue una encuesta de opiniones sobre el tipo de encuesta cuantitativa. Para la recolección de datos se utilizó la técnica Delphi para la construcción de una escala Likert. Utilizamos 3 rondas consecutivas para llegar a un consenso entre los informantes. Una muestra de la entrevista en 3 rondas consistió de 50 estudiantes, 25 hombres y 25 mujeres. Los estudiantes que apoyan la inserción de las nuevas tecnologías en la escuela y sugieren que esto podría estudiarse más a fondo. Hemos observado que el Educopédia todavía no es ampliamente utilizado en el aula. Todos los cursos tienen una baja utilización en la percepción de los estudiantes, especialmente Inglés, educación física y educación musical. Creemos que esta función requiere ajustes en su aplicación. Hay que centrarse más en la formación de profesores para trabajar con las nuevas tecnologías de proceso. Los juegos son uno de los recursos que los estudiantes Educopédia como y, al mismo tiempo, el menor uso en el aula. Esto ilustra que carecen de una estrategia que busca reconocer el perfil y el interés de los estudiantes.

PALABRAS CLAVE: Nuevas tecnologías. Revisar. Currículum.

\section{INTRODUÇÃO}

As novas tecnologias transformaram de modo significativo a comunicação, as relações interpessoais, o trabalho e as formas de decidir e pensar. A implantação de novas tecnologias no campo educacional tem sido uma consequência natural do acesso à informação e aos recursos no nosso cotidiano, bem como uma estratégia metodológica que possibilita facilitar o aprendizado discente.

Perrenoud (2000) questiona por que primeiro aprender pelos livros e só depois conhecer a comunicação por meio da informática. A inserção de novas tecnologias no processo educativo das escolas permite cumprir duas funções: aumentar a eficácia do ensino e familiarizar os alunos com as novas ferramentas digitais (PERRENOU, 2000).

Nesse sentido, o autor aponta que "preparar para as novas tecnologias é, para uma proporção crescente de alunos, atingir plenamente os mais ambiciosos objetivos da escola" (PERRENOUD, 2000, p. 128). Isso ocorre porque quando a escola centra seu ensino nas novas tecnologias oportuniza uma mudança de paradigma - daquele centralizado no aluno para o focado nas aprendizagens (TARDIF, 2002).

\begin{tabular}{l|l|l|l|l|l|l} 
(C) ETD-Educ. temat. digit. & Campinas, SP & v.16 & n.2 & p.346-361 & maio/ago. 2014 & ISSN 1676-2592 \\
\hline
\end{tabular}


De acordo com Perrenoud (2000) a utilização de novas tecnologias é uma das atuais competências que o professor deve possuir, realizando uma vigília cultural para compreender do que será feito a escola do amanhã.

Nesse sentido, Garcia et al. (2011) apontam competências necessárias para o uso de tais tecnologias no processo de ensino. Os autores organizam as diferentes competências em quatro categorias: tecnológica, pedagógica, sujeito e exploratória. Em resumo, os docentes devem possuir o domínio da tecnologia utilizada, possibilitar situações favoráveis ao aprendizado, valorizar as diferenças culturais dos alunos, conhecer as diferentes tecnologias e utilizá-las no processo de ensino.

Vale ressaltar que para os autores, a inserção de novas tecnologias na educação não deve ser encarada como um instrumento neutro, tendo por objetivo apenas facilitar o trabalho docente. Sua utilização no contexto escolar deve acontecer de forma a despertar a consciência crítica dos alunos acerca do tema (GARCIA et al., 2011).

Dentre as ações de inserção de novas tecnologias na educação carioca, têm se destacado a Educopédia, que é uma plataforma on-line de aulas digitais, em que alunos e professores podem acessá-la livremente; inclui planos de aula e apresentações, voltados para os docentes que queiram utilizar as atividades nas salas com as suas turmas. Cada uma delas cobrem temas, competências e habilidades das orientações curriculares da Secretaria Municipal de Educação do Rio de Janeiro (SME), sendo essas diretrizes anuais e particulares de cada disciplina, divididas em 32 aulas digitais, que correspondem às semanas do ano letivo.

A Educopédia iniciou no ano de 2010 e conta com uma parceria entre a Secretaria de Educação do Rio de Janeiro, o Ministério da Educação e Cultura (MEC) e o Instituto Oi Futuro. Para implantação do projeto têm sido entregue o Kit Educopédia (computador, projetor, caixa de som e internet $\mathrm{Wi}-\mathrm{Fi}$ ) para todas as escolas. $\mathrm{Na}$ entrega dos Kits, foram priorizadas as escolas que fazem parte do projeto experimental - Ginásio Experimental Carioca (GEC).

As pesquisas sobre novas tecnologias têm privilegiado apenas o enfoque dos professores. De fato, estes são atores fundamentais no processo de implementação de qualquer proposta na escola. Porém, é importante que os alunos sejam ouvidos, pois são 
igualmente relevantes no processo educacional (HAYDT, 2006). Nosso objetivo foi analisar os aspectos interferentes na utilização do projeto Educopédia sob a ótica dos alunos de uma escola experimental do Rio de Janeiro.

Escolhemos a Escola Municipal Independência por ser uma das primeiras instituições de ensino a receber e a fazer uso do Kit Educopédia e também por ser experimental.

\section{MÉTODO}

A metodologia desta pesquisa foi um levantamento de opiniões do tipo survey de natureza quantitativa. Para Gil (2002), essas pesquisas visam à realização direta de questionamentos aos atores sociais envolvidos 'no' ou 'com' o fenômeno ao qual se quer verificar. A pesquisa do tipo levantamento constitui-se em um modelo eficaz para dar suporte às pesquisas de caráter descritivo, principalmente quando o foco é o levantamento de opiniões e comportamentos de grupos sociais (AFONSO, 1992).

Escolhemos a técnica Delphi ${ }^{3}$ para a construção do instrumento de coleta de dados, por ela se caracterizar como uma forma de encontrar consenso entre os informantes sobre os aspectos relevantes da sua realidade (THOMAS; NELSON, 2002). De acordo com Linstone e Turoff (1975), a técnica Delphi se baseia em um processo estruturado de comunicação em grupo para chegar a determinados indicadores de consenso para a construção de instrumento de coleta de dados. Esse processo é constituído por rounds. Não há um acordo acerca do número ideal de rounds. Vale ressaltar que Linstone e Turoff (1975) apontam ainda, a utilização de três a quatro rounds. Já Chai (1977), apud Afonso (1992), indicam a possibilidade de se utilizar apenas dois rounds.

No presente estudo foi utilizada a técnica Delphi para a construção de um escala Likert para a coleta de dados. Utilizamos três rounds consecutivos para se alcançar um consenso entre os informantes.

No primeiro round, o procedimento se constituiu pela solicitação para que os alunos se oferecessem como voluntários para uma entrevista, na qual deveriam selecionar os itens que estariam interferindo negativa e positivamente na aplicação e utilização da Educopédia. Durante a entrevista, eles falaram abertamente, sem interrupções, mas sempre sendo

\footnotetext{
${ }^{3}$ Optamos pelo termo Técnica Delphi, pois entendemos que ela é um instrumento e não um conjunto de instrumentos, caracterizando-se como técnica e não como método.
} 
lembrados do tema proposto. No segundo round, apresentamos a lista de pontos citados no encontro anterior. Esses pontos foram discutidos de forma a gerar concordâncias e divergências. No terceiro round, foi apresentado um novo quadro de acordos e desacordos. Em seguida houve um debate sobre cada item novamente de forma a confirmar as opções. Após a discussão foi construída uma escala de opiniões do tipo Likert com cinco graus de concordância.

Os alunos responderam à escala Likert nas salas de aula, durante o horário escolar. Visitamos cada turma e explicamos os procedimentos e o preenchimento do instrumento.

A população da pesquisa foi composta por alunos da Escola Municipal Independência $^{4}$, no Rio de Janeiro, escolhida por ser uma das indicadas pela Secretaria Municipal de Educação do Rio de Janeiro para acolher o projeto GEC, que é um programa de escola integral com maior carga horária para as disciplinas e com uma proposta de atuar com interdisciplinaridade. As escolas ${ }^{5}$ do GEC foram as primeiras a utilizar a Educopédia e é onde tal recurso é utilizado de forma mais intensa.

A amostra da entrevista nos três rounds foi composta por 50 alunos, sendo 25 do sexo masculino e 25, do feminino. No preenchimento da escola Likert obtivemos um total de 246 alunos, correspondendo a $82,3 \%$ da população, sendo 132 do sexo masculino e 114 do sexo feminino. Participaram do estudo os alunos que estavam matriculados e frequentando do $7^{\circ}$ ao $9^{\circ}$ anos.

A técnica de análise de dados preconizada para a técnica Delphi é um tratamento estatístico, de característica descritiva, sedimentado no percentual de cada fator interferente identificado (AFONSO, 1992). Porém, há também uma perspectiva de análise qualitativa que objetiva analisar os consensos estabelecidos entre os atores do processo educativo. Dessa perspectiva, Bauer e Gaskel (2004) defendem que há sempre a necessidade de se interpretar os dados estatísticos, pois isso é qualificá-los.

A realização deste estudo contou com a aquiescência da Secretaria Municipal de Educação (SME) e da diretoria da escola, por meio de documento formal expedido no momento do início da pesquisa. Os responsáveis pelos alunos assinaram um Termo de Livre Consentimento Esclarecido autorizando a sua participação.

\footnotetext{
${ }^{4}$ Nome fictício.

${ }^{5}$ Até o momento da pesquisa existia um total de 10 escolas participando do projeto do GEC.

\begin{tabular}{l|l|l|l|l|l|l} 
(C) ETD - Educ. temat. digit. & Campinas, SP & v.16 & n.2 & p.346-361 & maio/ago. 2014 & ISSN 1676-2592 \\
\hline
\end{tabular}
} 


\section{RESULTADOS}

TABELA 1 - Computador e acesso à internet

\begin{tabular}{|c|c|c|c|c|c|c|}
\hline \multirow{2}{*}{ Questões } & \multicolumn{2}{|c|}{ Sim } & \multicolumn{2}{|c|}{ Não } & \multicolumn{2}{|c|}{$\mathrm{NR}^{1}$} \\
\hline & $\mathrm{N}^{\mathrm{o}}$ & $\%$ & $\mathrm{~N}^{\mathrm{o}}$ & $\%$ & $\mathrm{~N}^{\mathrm{o}}$ & $\%$ \\
\hline $\begin{array}{c}\text { Possui computador em } \\
\text { casa? }\end{array}$ & 230 & 93,5 & 13 & 5,3 & 2 & 0,8 \\
\hline $\begin{array}{c}\text { Possui acesso a internet } \\
\text { em casa? }\end{array}$ & 224 & 91,1 & 20 & 8,1 & 2 & 0,8 \\
\hline
\end{tabular}

Fonte: Próprios autores

Podemos verificar que o acesso e a utilização das novas tecnologias estão incorporados na vida dos alunos. A maioria relatou ter computador $(93,5 \%)$ e acesso à internet em casa $(91,5 \%)$, porém, mesmo aqueles que não a possuem apontaram usá-la frequentemente na casa de familiares, próximo às suas residências.

De acordo com o Ibope NetRatings ${ }^{6}$, o Brasil é o $5^{\circ}$ país mais conectado com a internet. Segundo pesquisa realizada pela Fecomércio-RJ/Ipsos ${ }^{7}$, o percentual de brasileiros que usam a internet aumentou de $27 \%$ para $48 \%$, entre 2007 e 2011. O principal local de acesso é a lan house (31\%), seguido da própria casa (27\%) e da casa de parente e de amigos, com $25 \%$. Portanto, podemos verificar que há um potencial a ser explorado nos alunos da escola Independência na medida em que possuem familiaridade e acesso à linguagem digital, o que torna essa estratégia mais suscetível ao êxito.

TABELA 2 - Uso da Educopédia

\begin{tabular}{|c|c|c|c|c|c|c|}
\hline Questões & Sempre & Frequentemente & Às Vezes & Pouco & Nunca & $\mathrm{NR}^{1}$ \\
\hline & $\mathrm{N}^{\mathrm{o}}$ & $\mathrm{N}^{\mathrm{o}}$ & $\mathrm{N}^{\mathrm{o}}$ & $\mathrm{N}^{\mathrm{o}}$ & $\mathrm{N}^{\circ}$ & $\mathrm{N}^{\mathrm{o}}$ \\
\hline
\end{tabular}

Na sua

opinião, como

a Educopédia é

$11 \quad 4,5 \quad 54$

22

10

40,7

utilizada na

\footnotetext{
${ }^{6}$ É um software, instalado em computadores de colaboradores escolhidos, de maneira a compor um painel representativo do universo de internautas brasileiros. Dessa maneira, são obtidos dados que detalham o comportamento dos usuários do meio digital.

${ }^{7}$ Disponível em: <http://www.fecomerciorj.org.br/publique/cgi/cgilua.exe/sys/start.htm>. Acesso em: 19/9/2013 \begin{tabular}{l|l|l|l|l|l|l} 
(C) ETD - Educ. temat. digit. & Campinas, SP & v.16 & n.2 & p.346-361 & maio/ago. 2014 & ISSN 1676-2592 \\
\hline
\end{tabular}
} 
escola?

Você Costuma

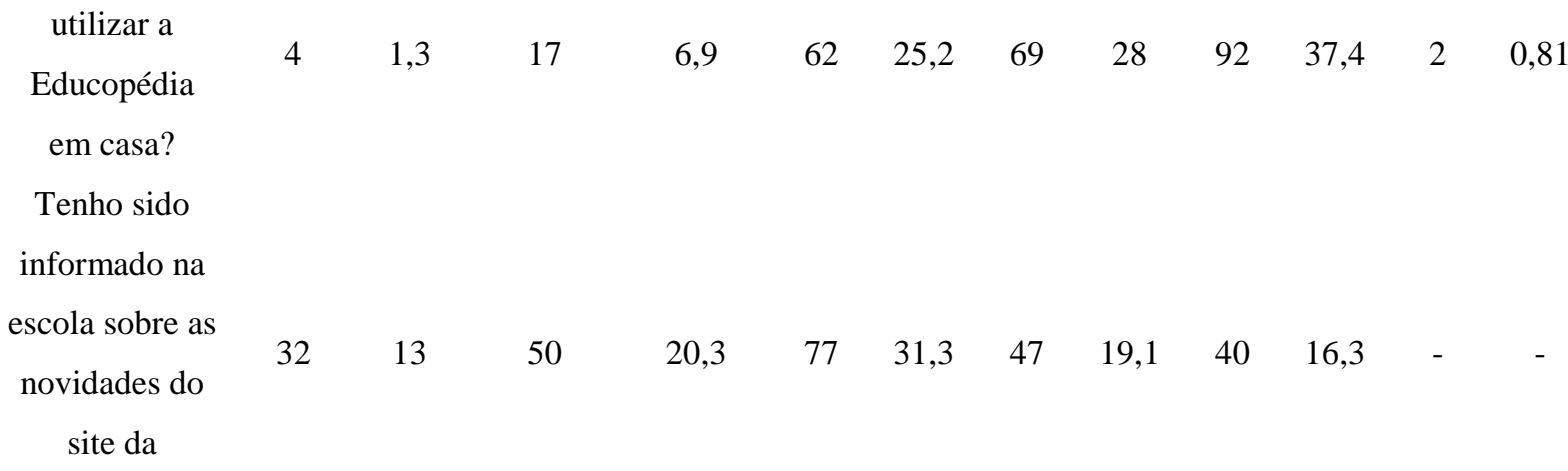

Educopédia

Fonte: Próprios autores

De acordo com a percepção dos alunos, a Educopédia ainda não é usada constantemente na sala de aula, pois apenas $26,5 \%$ dos entrevistados apontam que ela vem sendo utilizada "sempre" ou "frequentemente". A maior incidência repousa no indicador "às vezes" $(40,7 \%)$. Os dados mostram que os discentes não utilizam essa ferramenta em casa, por mais que os professores os informem sobre ela.

Para compreender melhor a pouca utilização da Educopédia temos que lembrar que a apropriação de qualquer inovação metodológica presente no currículo dialoga com questões culturais. A criação de um currículo não garante que os conteúdos, estratégias ou métodos sejam aplicados, visto que, mesmo servindo como um padrão a ser seguido, ainda é o professor quem decide o que utilizar em suas aulas (GIMENO SACRISTAN, 1998). Ao receber o currículo prescrito, o docente inicia um novo processo de seleção dos conteúdos, se tornando um mediador na sua aplicação. Seus critérios para essa escolha envolvem questões estruturais (materiais disponíveis, local e número de alunos), experiência profissional e questões de ordem social (DESTRO, 2004).

Goodson (2008) defende que para entender a construção do currículo, precisamos entendê-lo nos níveis de prescrição e do processo prático. A forma como os docentes interpretam as metodologias é fundamental para o sucesso dos projetos. Somente 8,2\% dos alunos responderam que usam a Educopédia "sempre" e "frequentemente" em casa, mesmo possuindo computador e acesso à internet. Tal descompasso ilustra uma subutilização dessa estratégia. Portanto, é necessário que haja um plano para que oriente, incentive e avalie a utilização dessa ferramenta metodológica nas escolas. Todavia, tal artifício deve se pautar em 
uma abordagem maior de orientação sobre o uso, evitando a construção de normatividades coercitivas sem qualquer esclarecimento.

TABELA 3 - Professores

\begin{tabular}{|c|c|c|c|c|c|c|c|c|c|c|c|c|}
\hline \multirow[t]{2}{*}{ Questões } & \multicolumn{2}{|c|}{$\begin{array}{c}\text { Concordo } \\
\text { plenamente }\end{array}$} & \multicolumn{2}{|c|}{$\begin{array}{c}\text { Concordo } \\
\text { parcialmente }\end{array}$} & \multicolumn{2}{|c|}{$\begin{array}{c}\text { Não } \\
\text { concordo } \\
\text { nem } \\
\text { discordo }\end{array}$} & \multicolumn{2}{|c|}{$\begin{array}{c}\text { Discordo } \\
\text { parcialmente }\end{array}$} & \multicolumn{2}{|c|}{$\begin{array}{c}\text { Discordo } \\
\text { plenamente }\end{array}$} & \multicolumn{2}{|c|}{ NR } \\
\hline & $\mathrm{N}^{\circ}$ & $\%$ & $\mathrm{~N}^{\circ}$ & $\%$ & $\mathrm{~N}^{\circ}$ & $\%$ & $\mathrm{~N}^{\circ}$ & $\%$ & $\mathrm{~N}^{\circ}$ & $\%$ & $\mathrm{~N}^{\circ}$ & $\%$ \\
\hline $\begin{array}{c}\text { Há professores } \\
\text { que possuem } \\
\text { dificuldade de } \\
\text { utilizar a } \\
\text { Educopédia e/ou } \\
\text { a tecnologia }\end{array}$ & 63 & 25,6 & 36 & 14,6 & 58 & 23,6 & 27 & 11 & 61 & 24,8 & 1 & 0,41 \\
\hline $\begin{array}{l}\text { Às vezes, alguns } \\
\text { professores não }\end{array}$ & & & & & & & & & & & & \\
\hline $\begin{array}{c}\text { o conteúdo que } \\
\text { está na } \\
\text { Educopédia }\end{array}$ & 42 & 17,1 & 47 & 19,1 & 71 & 28,9 & 32 & 13 & 54 & 22 & - & - \\
\hline $\begin{array}{l}\text { O material dos } \\
\text { professores no }\end{array}$ & & & & & & & & & & & & \\
\hline $\begin{array}{c}\text { PowerPoint } \\
\text { (slides) é melhor } \\
\text { que as aulas na } \\
\text { Educopédia }\end{array}$ & 124 & 50,4 & 55 & 22,4 & 48 & 19,5 & 4 & 1,6 & 11 & 4,5 & 4 & 1,6 \\
\hline $\begin{array}{l}\text { Há muitas partes } \\
\text { dentro da mesma }\end{array}$ & & & & & & & & & & & & \\
\hline $\begin{array}{c}\text { aula na } \\
\text { Educopédia que } \\
\text { o professor não } \\
\text { utiliza }\end{array}$ & 55 & 22,4 & 52 & 21,4 & 87 & 35,4 & 30 & 12,2 & 17 & 6,9 & 5 & 2 \\
\hline $\begin{array}{l}\text { Os trabalhos } \\
\text { para casa }\end{array}$ & & & & & & & & & & & & \\
\hline $\begin{array}{l}\text { poderiam ser } \\
\text { substituídos por } \\
\text { atividades no } \\
\text { Educopédia }\end{array}$ & 109 & 44,3 & 50 & 20,3 & 54 & 22 & 8 & 3,3 & 25 & 10,2 & - & - \\
\hline
\end{tabular}

Fonte: Próprios autores

Os alunos apontam que o conteúdo presente na Educopédia não é consenso entre os professores, na medida em que relatam que os docentes não concordam com alguns assuntos da Educopédia $(36,2 \%)$ ou que não utilizam alguma parte do conteúdo dentro da mesma aula \begin{tabular}{l|l|l|l|l|l|l} 
(C) ETD - Educ. temat. digit. & Campinas, SP & v.16 & n.2 & p.346-361 & maio/ago. 2014 & ISSN 1676-2592 \\
\hline
\end{tabular} 
$(43,8 \%)$.

Na opinião dos alunos há um grupo de professores que possuem dificuldades em atuar com as novas tecnologias (40,2\%). Entretanto, os entrevistados afirmaram que isso não é um problema, pois eles mesmos auxiliam os professores sempre que percebem tais dificuldades, como os docentes solicitarem a ajuda dos alunos em momentos adversos.

A maior parte dos alunos $(72,8 \%)$ aponta que o material que os professores utilizam, por vezes é melhor que os da Educopédia. A instalação de projetores para os professores utilizarem a Educopédia possibilitou a ampliação de recursos para produzirem as aulas, quer seja baixando o conteúdo da plataforma, quer seja adaptando as aulas da Educopédia com outros materiais. Esse movimento têm sido interessante uma vez que fornece materiais mais ajustados à realidade dos alunos, que parecem estar aprovando tal estratégia.

Podemos observar como o currículo vivido constrói sua autonomia relativa ao dialogar com os atores sociais (GOODSON, 1998). Neste caso em específico, nota-se que os pontos de dificuldades de aplicação da proposta, como a velocidade de conexão da internet e o conhecimento para lidar com novas tecnologias foi superado, gerando efeitos positivos. No caso da velocidade de conexão, os professores acabaram por adaptar as aulas da Educopédia, já que parte desse grupo discordava de alguns tópicos dos conteúdos, além de receberem auxílio dos próprios alunos, quando se deparavam com dificuldades relacionadas à tecnologia.

Parece que nessa realidade, a proposta de utilização foi bem acolhida entre os alunos, pois $64,6 \%$ apontaram que preferiam que os trabalhos para casa pudessem ser realizados com a Educopédia. Esse dado se torna mais relevante quando retomamos o baixo percentual $(8,2 \%)$ dos alunos que usam a plataforma em suas residências sempre ou frequentemente. Isso ilustra que talvez essa baixa utilização possa ser resolvida com apoio e pequenas mudanças na metodologia.

De acordo com Quevedo (2011) existe uma dificuldade para que o professor atue junto com as novas tecnologias, pois eles foram formados em ambientes em que tais recursos não eram utilizados e valorizados. Dessa forma, é necessária uma formação com esses profissionais que irão atuar com estas ferramentas, como a Educopédia. É neste sentido que Nóvoa (1992, p. 9), afirma que "não há ensino de qualidade, nem reforma educativa, nem inovação pedagógica, sem uma adequada formação de professores". Ensinar apenas a \begin{tabular}{l|l|l|l|l|l|l|} 
(c) ETD-Educ. temat. digit. & Campinas, SP & v.16 & n.2 & p.346-361 & maio/ago. 2014 & ISSN 1676-2592 \\
\hline
\end{tabular} 
utilização da plataforma da Educopédia é a primeira parte do processo, mas não a única.

TABELA 4 - A frequência de utilização da Educopédia nas disciplinas

\begin{tabular}{|c|c|c|c|c|c|c|c|c|c|c|c|c|}
\hline \multirow[t]{2}{*}{ Questões } & \multicolumn{2}{|c|}{ Sempre } & \multicolumn{2}{|c|}{ Frequentemente } & \multicolumn{2}{|c|}{ Às vezes } & \multicolumn{2}{|c|}{ Pouco } & \multicolumn{2}{|c|}{ Nada } & \multicolumn{2}{|c|}{ NR } \\
\hline & $\mathrm{N}^{\circ}$ & $\%$ & $\mathrm{~N}^{\circ}$ & $\%$ & $\mathrm{~N}^{\circ}$ & $\%$ & $\mathrm{~N}^{\circ}$ & $\%$ & $\mathrm{~N}^{\circ}$ & $\%$ & $\mathrm{~N}^{\circ}$ & $\%$ \\
\hline $\begin{array}{c}\text { Como a disciplina de } \\
\text { História usa a } \\
\text { Educopédia? }\end{array}$ & 11 & 4,5 & 24 & 9,8 & 73 & 29,7 & 86 & 35 & 52 & 21,1 & - & - \\
\hline $\begin{array}{l}\text { Como a disciplina de } \\
\text { Ciências usa a } \\
\text { Educopédia? }\end{array}$ & 6 & 2,4 & 17 & 6,9 & 75 & 30,5 & 91 & 37 & 56 & 22,8 & 1 & 0,4 \\
\hline $\begin{array}{l}\text { Como a disciplina de } \\
\text { Matemática usa a } \\
\text { Educopédia? }\end{array}$ & 17 & 6,9 & 43 & 17,5 & 78 & 31,7 & 68 & 27,6 & 39 & 15,9 & 1 & 0,4 \\
\hline $\begin{array}{c}\text { Como a disciplina de } \\
\text { Inglês usa a } \\
\text { Educopédia? }\end{array}$ & 2 & 0,8 & 8 & 3,3 & 33 & 13,4 & 45 & 18,3 & 157 & 63,8 & 1 & 0,4 \\
\hline $\begin{array}{c}\text { Como a disciplina de } \\
\text { Geografia usa a } \\
\text { Educopédia? }\end{array}$ & 14 & 5,7 & 41 & 16,7 & 92 & 37,4 & 64 & 26 & 35 & 14,2 & - & - \\
\hline $\begin{array}{l}\text { Como a disciplina de } \\
\text { Língua Portuguesa } \\
\text { usa a Educopédia? }\end{array}$ & 4 & 1,6 & 19 & 7,7 & 74 & 30,1 & 91 & 37 & 58 & 23,6 & - & - \\
\hline $\begin{array}{l}\text { Como a disciplina de } \\
\text { Educação Musical usa } \\
\text { a Educopédia? }\end{array}$ & 6 & 2,4 & 24 & 9,8 & 46 & 18,7 & 57 & 23,2 & 112 & 45,5 & 1 & 0,41 \\
\hline $\begin{array}{l}\text { Como a disciplina de } \\
\text { Educação Física usa a } \\
\text { Educopédia? }\end{array}$ & 1 & 0,4 & 3 & 1,2 & 2 & 0,8 & 11 & 4,5 & 228 & 92,7 & 1 & 0,4 \\
\hline
\end{tabular}

Fonte: Próprios autores

Acerca da frequência de utilização de cada disciplina, podemos perceber que todas apresentam um baixo uso da Educopédia, pois se somarmos os indicadores "sempre" e "frequentemente", nenhuma das disciplinas alcançam o percentual acima de $25 \%$ de utilização. Quando apontam aquelas que menos usam a ferramenta, destacam-se Inglês (63,8), Educação Musical (45,5\%) e Educação Física (92,7\%).

Conforme discutimos anteriormente, a utilização da Educopédia ainda não se encontra

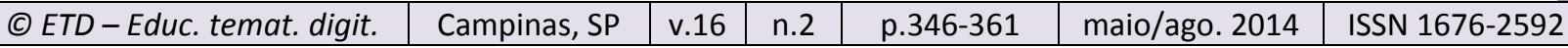


frequente nessa escola e a incorporação dessa ferramenta no cotidiano se deve a diversas estratégias no currículo vivido. Porém, surpreende, de certa forma, o fato de que nenhuma das disciplinas se destaque positivamente no uso desse recurso, o que nos faz pensar que possam existir barreiras mais específicas sobre a utilização da Educopédia no cotidiano dessa escola.

De acordo com Silva (2002) compreender o currículo exige a constante percepção da tensão existente entre os elementos internos das decisões sobre o currículo com as questões postas pela relevância daquilo que socialmente está estabelecido. E isso pode estar mais presente nas disciplinas: Educação Física, Inglês e Educação Musical, que receberam percentuais significativos de nenhuma utilização.

TABELA 5 - Educação Física e Educação Musical

\begin{tabular}{|c|c|c|c|c|c|c|c|c|c|c|c|c|}
\hline \multirow[t]{2}{*}{ Questões } & \multicolumn{2}{|c|}{$\begin{array}{l}\text { Concordo } \\
\text { plenamente }\end{array}$} & \multicolumn{2}{|c|}{$\begin{array}{c}\text { Concordo } \\
\text { parcialmente }\end{array}$} & \multicolumn{2}{|c|}{$\begin{array}{c}\text { Não } \\
\text { concordo } \\
\text { nem } \\
\text { discordo }\end{array}$} & \multicolumn{2}{|c|}{$\begin{array}{c}\text { Discordo } \\
\text { parcialmente }\end{array}$} & \multicolumn{2}{|c|}{$\begin{array}{c}\text { Discordo } \\
\text { plenamente }\end{array}$} & \multicolumn{2}{|c|}{$\begin{array}{c}\text { Não } \\
\text { respondeu }\end{array}$} \\
\hline & $\mathrm{N}^{\circ}$ & $\%$ & $\mathrm{~N}^{\circ}$ & $\%$ & $\mathrm{~N}^{\circ}$ & $\%$ & $\mathrm{~N}^{\circ}$ & $\%$ & $\mathrm{~N}^{\circ}$ & $\%$ & $\mathrm{~N}^{\circ}$ & $\%$ \\
\hline $\begin{array}{l}\text { Na disciplina } \\
\text { Educação }\end{array}$ & & & & & & & & & & & & \\
\hline $\begin{array}{l}\text { Física não é } \\
\text { necessário usar } \\
\text { a Educopédia }\end{array}$ & 130 & 52,8 & 30 & 12,2 & 42 & 17,1 & 15 & 6,1 & 28 & 11,4 & - & - \\
\hline $\begin{array}{l}\text { Na disciplina } \\
\text { Educação }\end{array}$ & & & & & & & & & & & & \\
\hline $\begin{array}{l}\text { Musical não é } \\
\text { necessário usar } \\
\text { a Educopédia }\end{array}$ & 67 & 27,2 & 37 & 15 & 58 & 23,6 & 37 & 15 & 46 & 18,7 & 1 & 0,4 \\
\hline
\end{tabular}

Fonte: Próprios autores

No que se refere à Educação Física e à Educação Musical, foi relatado que ambas são as menos atuantes com a Educopédia, no entanto, segundo os alunos, são as que menos precisam de tal recurso. Podemos perceber que os discentes naturalizam um entendimento acerca das disciplinas da Educação Física e da Educação Musical, classificando-as mais como atividades do que como componentes curriculares.

Essa falta de reconhecimento reforça a ideia de que essas disciplinas consideradas "mais práticas" não necessitam de conteúdos conceituais a serem desenvolvidos. Isso, por um lado, é fruto de uma percepção, mas também do resultado de como tais disciplinas e professores buscam se legitimar na relação de poder que se dá no currículo. Devemos olhar essas percepções como resultados de construções culturais construídas pelos atores sociais. 
De acordo com Silva (2002) e Goodson (2008), o currículo é construído socialmente por meio da interação dos atores sociais. Nesse sentido, tanto o imaginário de tais disciplinas quanto a forma com que os professores negociam o significado de suas disciplinas no cotidiano escolar, ajudam a construir significados desses componentes curriculares.

De fato, a Educação Física e Musical são disciplinas que sempre buscaram maior legitimidade no cotidiano escolar por serem consideradas menos importantes (SOUZA JUNIOR; SANTIAGO; TAVARES, 2011). De uma forma geral, há no modelo de escola ocidental uma valorização dos conhecimentos relacionados à racionalidade formal em detrimento das experiências artísticas e de movimento (FREIRE; OLIVEIRA, 2004). Isso quer dizer que ambas dialogam com tais influências na disputa social do currículo. Esse caráter "mais prático" pode revelar um determinado lugar no currículo da escola que muitas vezes diminui a possibilidade de contestação no mapa cultural em que está inserido. Há que se repensar as formas de tais disciplinas atuarem com a Educopédia, assim como reforçar a necessidade e o benefício que tal ferramenta poderia possibilitar, inclusive na negociação cultural do currículo.

TABELA 6 - Usuabilidade

\begin{tabular}{|c|c|c|c|c|c|c|c|c|c|c|c|c|}
\hline \multirow[t]{2}{*}{ Questões } & \multicolumn{2}{|c|}{$\begin{array}{l}\text { Concordo } \\
\text { plenamente }\end{array}$} & \multicolumn{2}{|c|}{$\begin{array}{c}\text { Concordo } \\
\text { parcialmente }\end{array}$} & \multicolumn{2}{|c|}{$\begin{array}{c}\text { Não } \\
\text { concordo } \\
\text { nem } \\
\text { discordo }\end{array}$} & \multicolumn{2}{|c|}{$\begin{array}{c}\text { Discordo } \\
\text { parcialmente }\end{array}$} & \multicolumn{2}{|c|}{$\begin{array}{c}\text { Discordo } \\
\text { plenamente }\end{array}$} & \multicolumn{2}{|c|}{$\begin{array}{c}\text { Não } \\
\text { respondeu }\end{array}$} \\
\hline & $\mathrm{N}^{\circ}$ & $\%$ & $\mathrm{~N}^{\circ}$ & $\%$ & $\mathrm{~N}^{\circ}$ & $\%$ & $\mathrm{~N}^{\circ}$ & $\%$ & $\mathrm{~N}^{\circ}$ & $\%$ & $\mathrm{~N}^{\circ}$ & $\%$ \\
\hline $\begin{array}{l}\text { O uso de } \\
\text { tecnologia ajuda a } \\
\text { aprender melhor }\end{array}$ & 199 & 80,9 & 29 & 11,8 & 12 & 4,9 & 2 & 0,8 & 4 & 1,6 & - & - \\
\hline $\begin{array}{l}\text { As aulas na } \\
\text { Educopédia } \\
\text { proporcionam }\end{array}$ & & & & & & & & & & & & \\
\hline $\begin{array}{c}\text { maior } \\
\text { interatividade } \\
\text { entre os alunos e o } \\
\text { professor }\end{array}$ & 89 & 36,2 & 51 & 20,7 & 77 & 31,3 & 8 & 3,3 & 19 & 7,7 & 2 & 0,8 \\
\hline $\begin{array}{l}\text { As aulas na } \\
\text { Educopédia }\end{array}$ & & & & & & & & & & & & \\
\hline $\begin{array}{l}\text { proporcionam } \\
\text { maior } \\
\text { interatividade dos } \\
\text { alunos com o }\end{array}$ & 100 & 40,7 & 56 & 22,8 & 57 & 23,2 & 16 & 6,5 & 14 & 5,7 & 3 & 1,2 \\
\hline
\end{tabular}


conteúdo

Fonte: Próprios autores

Podemos observar que somados os percentuais de concordância, os alunos pesquisados apontam que a inserção dessa nova tecnologia possibilitou um aprendizado mais significativo (92,7\%). Esses dados divergem da percepção de alunos do ensino semipresencial (QUEVEDO, 2011). Entretanto, apenas aproximadamente a metade dos entrevistados concorda que as aulas proporcionam maior interatividade com o professor $(56,9 \%)$ e com o conteúdo $(63,5 \%)$. Isso revela que mesmo a Educopédia sendo uma estratégia dotada de ineditismo, esta ainda não consegue alterar a metodologia do professor, sendo um efeito da interação do currículo prescrito com o cotidiano.

Gimeno Sacristán (1998) aponta que no final do processo é o professor que seleciona o que vai trabalhar e a forma como vai atuar. Para que possamos utilizar uma metodologia inovadora, é necessário mais que capacitar e incentivar os professores: é importante ouvi-los, pois eles são elementos fundamentais no processo de implantação de qualquer metodologia na escola.

Na mesma direção, Quevedo (2011), investigando um grupo de alunos de uma turma semipresencial, apontou que a principal insatisfação relatada por eles é a pouca interação com os pares. Tais dados reforçam o argumento de que é necessário não apenas um recurso, mas uma formação e uma metodologia aplicada à tecnologia.

TABELA 7 - Recursos

\begin{tabular}{|c|c|c|c|c|c|c|c|c|c|c|c|c|}
\hline \multirow[t]{2}{*}{ Questões } & \multicolumn{2}{|c|}{ Textos } & \multicolumn{2}{|c|}{ Vídeos } & \multicolumn{2}{|c|}{ Jogos } & \multicolumn{2}{|c|}{$\begin{array}{l}\text { Educoquiz } \\
\text { (perguntas) }\end{array}$} & \multicolumn{2}{|c|}{$\begin{array}{c}\text { Educosíntese } \\
\text { (resumos) }\end{array}$} & \multicolumn{2}{|c|}{$\begin{array}{c}\text { Não } \\
\text { respondeu }\end{array}$} \\
\hline & $\mathrm{N}^{\circ}$ & $\%$ & $\mathrm{~N}^{\circ}$ & $\%$ & $\mathrm{~N}^{\circ}$ & $\%$ & $\mathrm{~N}^{\circ}$ & $\%$ & $\mathrm{~N}^{\circ}$ & $\%$ & $\mathrm{~N}^{\circ}$ & $\%$ \\
\hline $\begin{array}{l}\text { Qual o recurso da } \\
\text { Educopédia que } \\
\text { você mais usa em } \\
\text { sala de aula? }\end{array}$ & 94 & 38,2 & 41 & 16,7 & 13 & 5,3 & 60 & 24,4 & 19 & 7,7 & 19 & 7,7 \\
\hline $\begin{array}{l}\text { Qual o recurso da } \\
\text { Educopédia de } \\
\text { que você mais } \\
\text { gosta? }\end{array}$ & 6 & 2,4 & 37 & 15 & 125 & 50,8 & 47 & 19,1 & 12 & 4,9 & 19 & 7,7 \\
\hline $\begin{array}{l}\text { Qual o recurso da } \\
\text { Educopédia de } \\
\text { que você menos }\end{array}$ & 135 & 54,9 & 17 & 6,9 & 13 & 5,3 & 20 & 8,1 & 40 & 16,3 & 21 & 8,5 \\
\hline
\end{tabular}


gosta?

Fonte: Próprios autores

Podemos observar que há um descompasso na aplicação dos recursos em relação ao gosto dos alunos. O texto é o artifício mais usado $(38,2 \%)$ nas aulas, entretanto é aquele que os discentes menos gostam (54,9\%). O jogo, em contrapartida, é o favorito (50,8\%), mas é o menos utilizado (5,3\%). É consenso no campo educacional que o uso de jogos de diferentes tipos favorece o aprendizado de conteúdos escolares (KISHIMOTO, 1996). Porém, a falta de tais materiais ainda dificulta a sua implantação nas escolas.

Devemos ficar atentos no que se refere à linguagem do gosto, que foi se impondo, sendo hoje o aspecto mais dominante para expressar a construção do "eu pessoal" e dos vínculos sociais baseados na emotividade, na autenticidade e na originalidade (LOVISOLO, 2000). Portanto, há um desafio entre privilegiar a linguagem do gosto sem cair na armadilha de ensinar somente o que os alunos gostam.

\section{CONSIDERAÇÕES FINAIS}

A Educopédia ainda não é utilizada amplamente nas aulas da Escola Municipal Independência. Todas as disciplinas possuem baixa utilização na percepção dos alunos, com destaque para Inglês, Educação Musical e Educação Física. Isso mostra que tal recurso necessita de ajustes em sua aplicação. É necessário maior foco no processo de formação de docentes para atuarem com as novas tecnologias. Saber usar o recurso não significa que os professores vão incorporá-los nas suas rotinas de aulas. A falta de uma formação voltada para o uso das novas tecnologias vai resultar em poucas mudanças na metodologia utilizada pelos professores. É necessário um processo específico de formação para os docentes, afinal, eles são os responsáveis pela implementação desses procedimentos em suas turmas (GIMENO SACRISTAN, 1998).

A Educopédia é um método que possui um potencial de impacto significativo na medida em que os alunos têm acesso às novas tecnologias no seu cotidiano. Porém, ainda são necessárias ações que busquem aproveitar melhor esse potencial nas tarefas fora da escola, como a substituição dos trabalhos de casa por atividades na Educopédia.

Os jogos são um dos recursos da Educopédia que os alunos mais gostam e, ao mesmo 
tempo, o que menos usam nas aulas. Isso ilustra que falta uma estratégia que busque reconhecer o perfil e o interesse dos discentes. É importante ajustar esse mecanismo ao gosto de seu público, pois o gosto é uma linguagem essencial no aprendizado (LOVISOLO, 2000). Todavia, essa adaptação não deve ficar presa apenas ao que os alunos gostam, pois se corre o risco de lesar o próprio processo educativo.

A construção de recursos apoiados nas novas tecnologias como a Educopédia, é o exemplo de uma sensibilização para a implementação de ferramentas inovadoras no campo da educação. Tais iniciativas buscam alterar a metodologia das aulas. Porém, como pudemos observar, é necessário que os gestores educacionais compreendam que a implantação de um novo processo deve passar antes de tudo por uma formação e um estímulo ao uso dos professores.

\section{REFERÊNCIAS}

AFONSO, Mariangela da Rosa. Aspectos interferentes na qualidade dos programas de mestrado em Educação Física no Brasil: um estudo descritivo. 1992. 107f. Dissertação (Mestrado em Educação Física) - Universidade Gama Filho, Rio de Janeiro, 1992.

BAUER, Martin.; GASKEL, George. Pesquisa qualitativa com texto, imagem e som: um manual prático. 3. ed. Petrópolis: Vozes, 2002.

DESTRO, Denise de Souza. A política curricular em Educação Física do Município de Juiz de Fora-MG: hibridismo entre o contexto de produção do texto político e o contexto da prática. 2004. 168f. Dissertação (Mestrado Educação) - Universidade Estadual do Rio de Janeiro, Rio de Janeiro, 2004.

FREIRE, Elisabete dos Santos.; OLIVEIRA, José Guilmar Mariz de. Educação Física no Ensino Fundamental: identificando o conhecimento de natureza conceitual, procedimental e atitudinal. Motriz, Rio Claro, v.10, n.3, p. 140-151, set./dez. 2004. Disponível em: <http://www.rc.unesp.br/ib/efisica/motriz/10n3/07FES.pdf >.Acesso em: 10 Jan. 2014.

GARCIA, Marta Fernandes. Novas competências docentes frente às tecnologias digitais interativas. Rev. Teoria e Prática da Educação, v. 14, n. 1, p. 79-87, jan./abr. 2011. Disponível em: 〈http://eduem.uem.br/ojs/index.php/TeorPratEduc/article/view/16108/8715>. Acesso em: 07 Ago. 2014.

GIMENO SACRISTAN, José. O currículo: uma reflexão sobre a prática. Porto Alegre: ArtMed, 1998.

GOODSON, Ivor. Currículo: teoria e história. Petrópolis: Vozes, 2008.

HAYDT, Regina Celia. Curso de didática geral. 8. ed. São Paulo: Ática, 2006. 
KISHIMOTO, Tizuko Morchida. Jogo, brinquedo, brincadeira e a educação. São Paulo: Cortez, 1996.

LINSTONE, Harrold.; TUROFF, Murray (Ed.). The Delphi method: techniques and applications. Reading, MA: Addison-Wesley Publishing, 1975.

LOVISOLO, Hugo. Atividade física, educação e saúde. Rio de Janeiro: Sprint, 2000. NÓVOA, Antonio. Os professores e a sua formação. Lisboa: Dom Quixote, 1992.

PERRENOUD, Phileppe. 10 novas competências para ensinar. Porto Alegre: Artmed, 2000 .

QUEVEDO, Angelita. O ensino semipresencial do ponto de vista do aluno. Revista ecurriculum, São Paulo, v.7, n.1, p. 1-21, Abril. 2011. Disponível em: $<$ http://revistas.pucsp.br/index.php/curriculum/article/viewFile/5678/4004>. Acesso em: 15 Dez. 2013.

SILVA, Tomas Tadeu da. Documentos de identidade: uma introdução às teorias do currículo. 2.ed. Belo Horizonte: Autêntica, 2002.

SOUZA JUNIOR, Marcícilo.; SANTIAGO, Eliete.; TAVARES, Marcelo. Currículo e saberes escolares: ambigüidades, dúvidas e conflitos. Pro-posições, Campinas, v. 22, n. 1, p. 183-196, jan./abr. 2011. Disponível em: 〈http://www.scielo.br/pdf/pp/v22n1/14.pdf>. Acesso em: 5 fev. 2014.

TARDIF, Maurice. Saberes docentes e formação profissional. Petrópolis: Vozes, 2002.

THOMAS, Jerry.; NELSON, Jack. Métodos de pesquisa em educação física. 3. ed. São Paulo: Artmed, 2002.

\section{Como citar este documento:}

MOURA, Diego Luz; SOUSA, Cleyton Batista. A utilização das novas tecnologias em uma escola experimental do Rio de Janeiro. ETD - Educação Temática Digital, Campinas, SP, v. 16, n. 2, p. 346361, maio/ago. 2014. ISSN 1676-2592. Disponível em: <http://www.fe.unicamp.br/revistas/ged/ etd/article/view/6458>. Acesso em: 29 ago. 2014. 